\title{
A New Material Based on Clay and its Successful Application to Fix the Glucose
}

\section{BOUMETHRED TORKIA ${ }^{1,2 *}$, BENGUEDDACH ABEDELKADER ${ }^{1}$ and HAOUZI AHMED ${ }^{2}$}

${ }^{1}$ Chemistry Materials Laboratory, University of Ahmed Benbella Oran 1, 31000, Algeria. ${ }^{2}$ Synthesis and Catalysis Laboratory, University of Ibn Khaldoun Tiaret, 14000, Algeria.

${ }^{*}$ Corresponding author E-mail: boumetred @ yahoo.fr

http://dx.doi.org/10.13005/ojc/330145

(Received: December 08, 2016; Accepted: February 07, 2017)

\begin{abstract}
The aim of the present study is to seta new material based on clay and its application to fix the glucose. Montmorillonite KSF-Fe ${ }^{2+}$ were prepared by varying the exchange time ( $3 \mathrm{~h}, 8 \mathrm{~h}$, and $\left.11 \mathrm{~h}\right)$. These samples were identified as $\mathrm{FM}_{3}, \mathrm{FM}_{8}$, and $\mathrm{FM}_{11}$, respectively. Glucose level was determined using the enzymatic reaction. The adsorption kinetic of glucose, by the studied samples, showed that the $\mathrm{FM}_{8}$ gives a better fixation of glucose $(40,5 \%)$. Characteristics of the samples were studied by X-ray diffraction (XRD), Fourier transform infrared spectroscopy (IR), thermogravimetry (ATG) and Mossbauer spectroscopy. The X-ray diffraction (XRD) afforded the slight evolution of the interlayer distance $d_{001}$ during cation exchange. The IR spectrum of $F M_{8}-G$ ( Material loaded with glucose) show appearance of new band at $1150 \mathrm{~cm}^{-1}$ correspond to $\mathrm{nC}-\mathrm{O}$ and Another band located around $1420 \mathrm{~cm}^{-1}$ is assigned $\delta \mathrm{CH}_{2}+\delta \mathrm{OCH}+\delta \mathrm{CCH}$. Thermogravimetric analysis(TGA) confirms the binding of glucose there is a loss of weight around $350^{\circ} \mathrm{C}$ and $410^{\circ} \mathrm{C}$ corresponds to the decomposition of the glucose. The study of the mossbauer spectrum of $\mathrm{FM}_{8}$ were carried out the state of oxidation of ferrous ions in montmorillonite structure. This result could confirm that the fixation of glucose was achieved successfully.
\end{abstract}

Keywords: Montmorillonite KSF, Ferrous ion, Adsorption, Glucose.

\section{INTRODUCTION}

There are a wide variety of argillaceous rocks, depending on their structure and mineralogical composition, of which only few are used in medical therapy ${ }^{1}$. Each of these clays can, very often, shows some specific therapeutic virtues. Although they present in general a number of similar properties that characterize them.
The montmorillonite studied in the present work are of colloidal clays ${ }^{2}$, which received multiple applications, dueto their high exchange capacity and swelling as well as their rheological properties (thixotropy) ${ }^{3}$. They are therefore used in various fields such as drilling, foundry, ceramics, pharmacy, ... etc. 
In the present study we aimed to use a material and a compensating cation in which the retention of glucose is the most important $\left(\mathrm{KSF}-\mathrm{Fe}^{2+}\right)$. The kinetics of contact between clay and solutions of glucose was investigated to search for an optimal time giving a better retention. In this article, the results obtained by the combined use of X-ray diffraction, $\mathrm{IR}$, thermal analysis and Mossbauer spectroscopy are described. These analyses were carried out with the objective of determining the state of the iron in montmorillonite structure, and to characterize the interaction between montmorillonite exchanged By ferrous ions and glucose.

\section{EXPERIMENT}

\section{Preparation of the adsorbents}

All experiments in this work were carried out on a same bacthof montmorillonite KSF supplied by Aldrich. It is a commercial montmorillonite, calciumrich form of gray powder.
The mass ratios of oxides of the elements forming this clay are given in Table 1.

\section{The exchange by $\mathrm{Fe}^{2+}$}

The cation exchange $\mathrm{Fe}^{2+}$ was selected based on its capacity to form a complex with glucose.

In order to investigate the potential fixation of glucose, three materials referenced as $\mathrm{FM}_{3}, \mathrm{FM}_{8}$ and $\mathrm{FM}_{11}$ were prepared and subjected to a cation exchange with ferrous ions by varying the exchange time as indicated in following chart (Fig.1). The studied materials were then characterized.

\section{Determination of glucose}

The determination of glucose was achieved by an enzymaticmethod reaction, as described previously ${ }^{5,6}$. The assessments were performed using a spectrophotometer (Shimadzu Corporation, Japan 1200 UV). The peak wavelengths were obtained

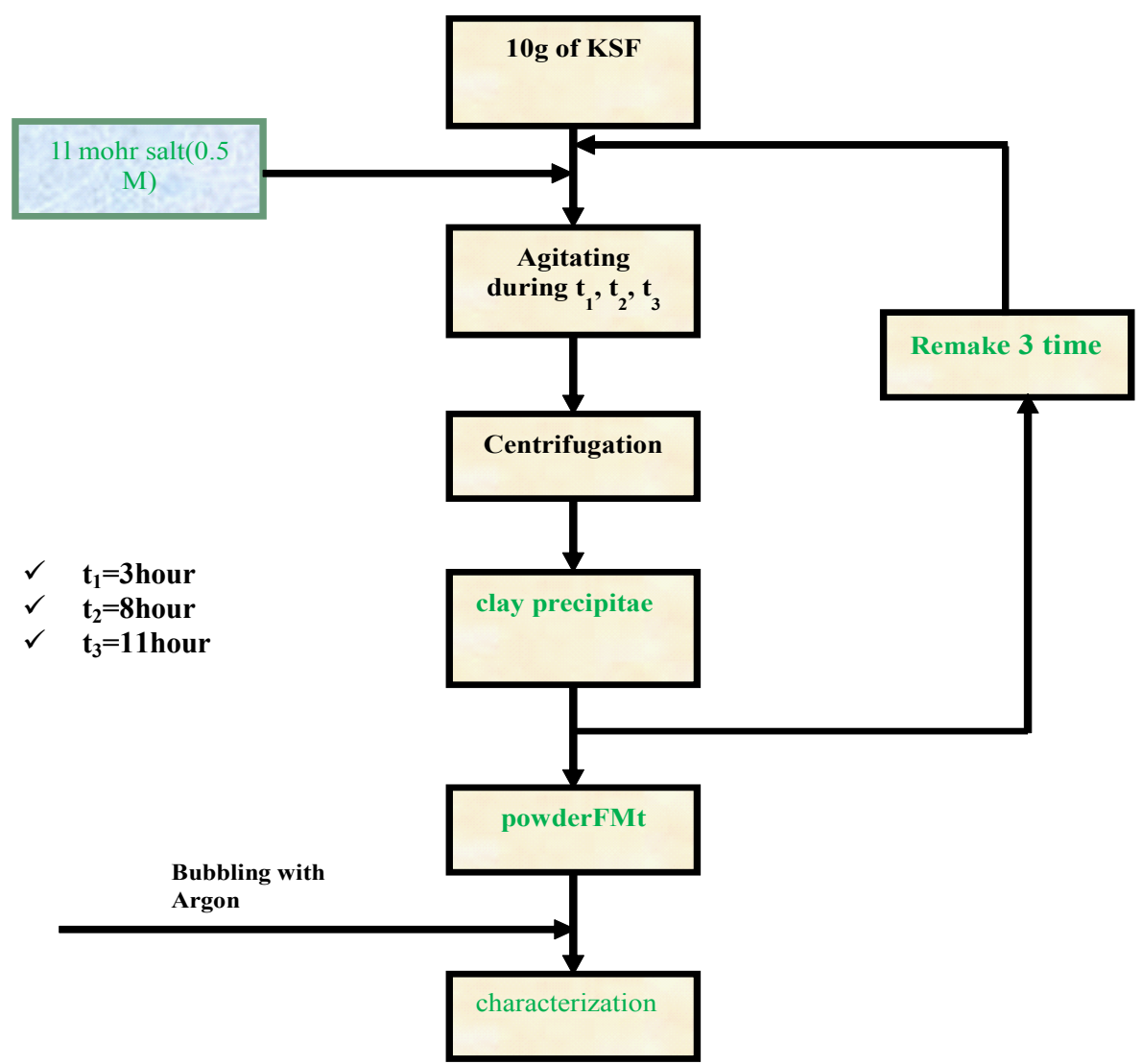

Fig.1: Diagram represents the exchange of KSF by ferrous ions 
directly by an automatic scanning between 200 to $800 \mathrm{~nm}$.

\section{Principle}

Glucose is oxidised to gluconic acid and hydrogen peroxide in the presence of glucose oxidase. Hydrogen peroxide further reacts with phenol and 4-aminoantipyrine by the catalytic action of peroxidase to form a red coloured quinoneimine dye complex. Intensity of the colour formed is directly proportional to the amount of glucose present in the sample s,8,9. $^{7,8}$.

\section{Glucose Oxidase}

Glucose $+\mathrm{O}_{2}+\mathrm{H}_{2} \mathrm{O} \longrightarrow$ Gluconate $+\mathrm{H}_{2} \mathrm{O}_{2}$

$\mathrm{H}_{2} \mathrm{O}_{2}+4$ Aminoantipyrine+ Phenol $\longrightarrow$ Red

+ Quinoneimine dye $+\mathrm{H}_{2} \mathrm{O}$

\section{PROCEDURE}

Wavelength: $505 \mathrm{~nm}$

Temperature: $37^{\circ} \mathrm{C}$

Light path: $1 \mathrm{~cm}$
Addition Sequence Blank(ml) Standard Test

\begin{tabular}{lccc}
\hline Glucose Reagent (L1) & $1(\mathrm{ml})$ & $1(\mathrm{ml})$ & $1(\mathrm{ml})$ \\
Distilled water & $1(\mu \mathrm{l})$ & - & - \\
Glucose standard & - & $1(\mu \mathrm{l})$ & - \\
Sample & - & - & $1(\mu \mathrm{l})$ \\
\hline
\end{tabular}

Mix well and incubate at $37^{\circ} \mathrm{C}$ for 10 mins,

Measure absorbance of the Standard (Abs.S) and Test Sample (Abs.T)

\section{Calculations}

$$
\text { Total Glucose in mg/dl }=\frac{\text { Abs.T }}{\text { Abs.S }} \times 100
$$

\section{Adsorption kinetics}

It was necessary to follow the kinetics of the adsorption of glucose to determine the conditions for maximal binding. For this, three suspensions containing $250 \mathrm{ml}$ of glucose solution at $2 \mathrm{~g} / \mathrm{l}$ and $1.5 \mathrm{~g}$ $\mathrm{FM}_{3}, \mathrm{FM}_{8}$ and $\mathrm{FM}_{11}$, were kept under stirring followed

Table 1: Chemical composition (in wt \%) of montmorillonite $\mathrm{KSF}^{4}$

\begin{tabular}{lllllllllll}
\hline Oxide & $\mathrm{Al}_{2} \mathrm{O}_{3}$ & $\mathrm{SiO}_{2}$ & $\mathrm{Na}_{2} \mathrm{O}$ & $\mathrm{MgO}$ & $\mathrm{P}_{2} \mathrm{O}_{5}$ & $\mathrm{~K}_{2} \mathrm{O}$ & $\mathrm{CaO}$ & $\mathrm{TiO}_{2}$ & $\mathrm{MnO}$ & $\mathrm{Fe}_{2} \mathrm{O}_{3}$ \\
\hline$\%$ & 14.93 & 69.31 & 0.14 & 2.19 & 0.09 & 1.17 & 2.08 & 0.44 & 0.01 & 3.97 \\
\hline
\end{tabular}

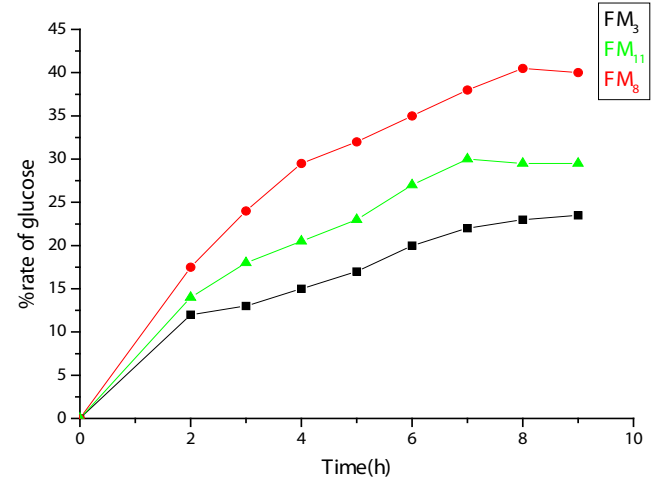

Fig. 2: The \% rate of the adsorption of glucose by the studied materials: $\mathrm{FM}_{3}, \mathrm{FM}_{11}, \mathrm{FM}_{8}$

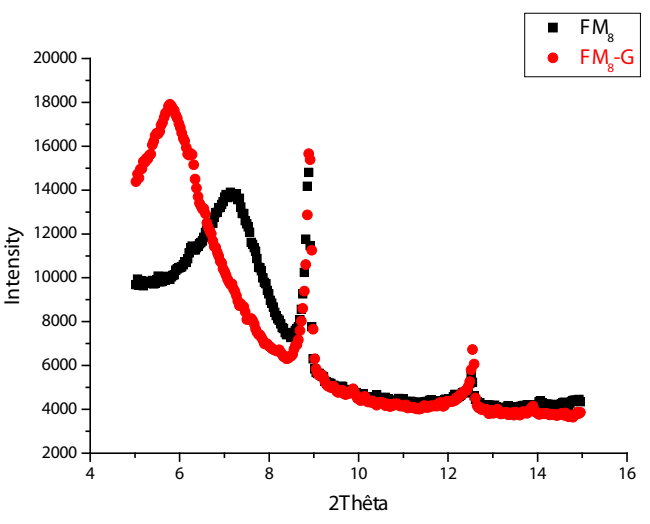

Fig. 3: X-ray powder patterns of the studied samples $\mathrm{FM}_{8}$ and $\mathrm{FM}_{8}-\mathrm{G}$ 
by a centrifugation at $4500 \mathrm{rpm} / \mathrm{min}$ then assayed as described above.

\section{RESULTS AND DISCUSSIONS}

\section{Adsorption kinetics}

As shown in the (Fig 2), the maximum adsorption rate for the three materials used ( $\mathrm{FM}_{3}$,
$\mathrm{FM}_{8}$, and $\left.\mathrm{FM}_{11}\right)$ are $23.5 \%, 40.5 \%$ and $29.5 \%$, respectively.

$$
\text { Interestingly, the } \mathrm{FM}_{8} \text { material, prepared }
$$
using $\mathrm{Fe}(\mathrm{II})$ exchanged montmorillonite KSF for an exchange time of 8 hours gives an adsorption rate of $40.5 \%$ glucose, which is much higher when

Table 3: Mossbauer parameters at room temperature of $\mathrm{FM}_{8}$

\begin{tabular}{cccccccccccccc}
\hline $\mathbf{F M}_{\mathbf{8}}$ & \multicolumn{3}{c}{ IS, $\mathbf{m m}$ /s } & \multicolumn{3}{c}{ QS, $\mathbf{m m}$ /s } & \multicolumn{2}{c}{ LW, $\mathbf{m m} \mathbf{s}$} & \multicolumn{3}{c}{ Contribution \% } \\
\hline Comp1 & 1.09 & \pm & 0.02 & 2.00 & \pm & 0.03 & 0.32 & \pm & 0.03 & 13 & \pm & 5 \\
Comp2 & 1.06 & \pm & -1.00 & 2.82 & \pm & -1.00 & 0.23 & \pm & -1.00 & 2 & \pm & -1 \\
Comp3 & 0.36 & \pm & 0.00 & 1.21 & \pm & 0.01 & 0.30 & \pm & 0.02 & 38 & \pm & 5 \\
Comp4 & 0.36 & \pm & 0.01 & 0.68 & & 0.07 & 0.56 & \pm & 0.06 & 34 & \pm & 7 \\
Comp5 & 0.44 & \pm & 0.01 & 0.22 & \pm & 0.03 & 0.31 & \pm & 0.08 & 12 & \pm & 4 \\
\hline
\end{tabular}

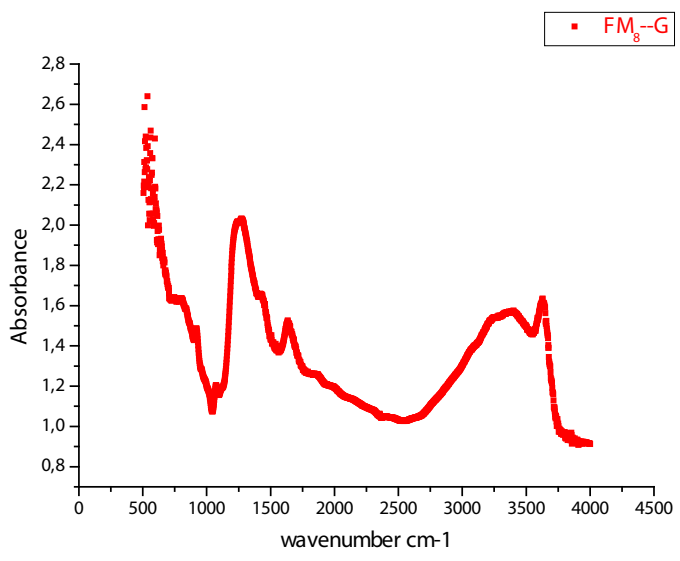

Fig. 4: Infrared spectrum of $\mathrm{FM}_{8}-\mathrm{G}$

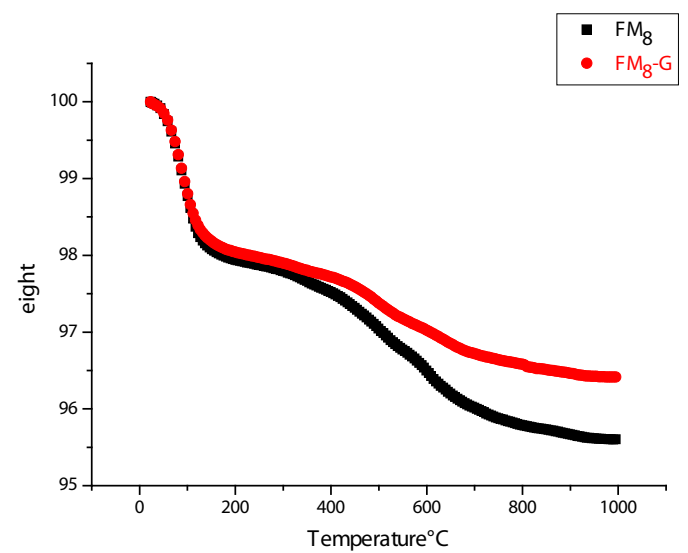

Fig. 5. Thermal gravimetricanalysis of studied samples $\mathrm{FM}_{8}$ and $\mathrm{FM}_{8}-\mathrm{G}$

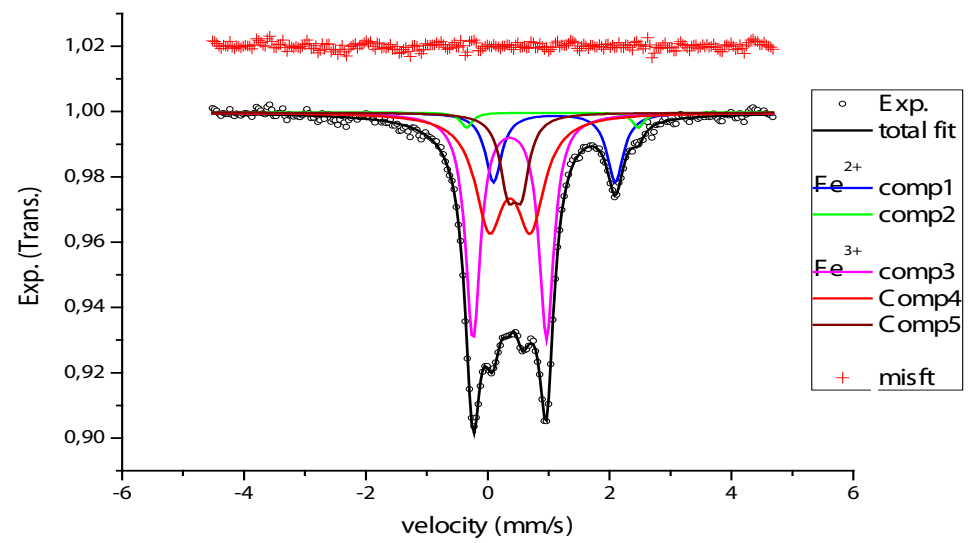

Fig. 6: Room temperature Mossbauer spectrum of FM8 sample 
compared to those obtained with the other two materials $\left(\mathrm{FM}_{3}\right.$ and $\left.\mathrm{FM}_{11}\right)$.

\section{Characterization by XRD}

Powder pattern where recorded on a PHILIPS X'Pert MPD $\lambda$ - $\lambda$ diffractometer equipped with the $X^{\prime}$ Celerator detector with Cu Ká radiation $(\lambda=1.5418 \AA)$ and nickel filter »The different results regarding the XRD characterization of the studied samples are summarized in the Fig.3. Examination of this recorded diffractogram and peak list show that the basic structure of the aluminosilicates is maintained and the values of angle are bands q2 Characteristics of montmorionite. It seems clearly that the distance $\mathrm{d}_{001}$ of exchanged montmrillonite by ions ferrous affected a slight change in the inter-fowl distanceafter the fixation of glucose.

\section{Characterization by IR}

The use of infrared spectroscopy allows determining information about the different absorption bands existing in the material $\mathrm{FM}_{8}-\mathrm{G}$. The IRTF spectrum examination (Fig. 4) shows the following bands: An intense strip at $3450 \mathrm{~cm}^{-1}$ and a strip at about $1630 \mathrm{~cm}^{-1}$; Are relative to the modes of vibration of the water molecules adsorbed in the inter-sheet space ${ }^{10,11,12}$, the bands located around $1050 \mathrm{~cm}^{-1}$ and $910 \mathrm{~cm}^{-1}$ and $840 \mathrm{~cm}^{-1}$ are assigned respectively to the "Elongation of the Si-O bond; The deformation of the Al-Al-OH bond and the deformation of the Al-Mg-OH bond, the band located around $780 \mathrm{~cm}^{-1}$ is due to the elongation vibration of the bond Si-O bond ${ }^{13,14}$, we noticed an appearance of new band at $1150 \mathrm{~cm}^{-1}$ correspond ton C-O and Another band located around $1420 \mathrm{~cm}^{-1}$ is assigned $\delta \mathrm{CH}_{2}+\delta \mathrm{OCH}+\delta \mathrm{CCH}$.

This result could confirm that the fixation of glucose was achieved successfully.

\section{Thermal gravimctric analysis}

The process of weight loss can be devised two stapes the first weight loss observed Around $100^{\circ} \mathrm{C}$ is attributed to the desorption of water (with may be physical or chemical adsorption on the interpaticle surface of two samples $\left(\mathrm{FM}_{8}\right.$ and $\mathrm{FM}_{8}-\mathrm{G}$ ), the second stap from 560 to $600^{\circ} \mathrm{C}$ with the main weight loss can correspond to the weight loss caused by breaking the Calcite ${ }^{15}$. In the sample $\mathrm{FM}_{8}-\mathrm{G}$ there is a loss of weight around $350^{\circ} \mathrm{C}$ and $410^{\circ} \mathrm{C}$ corresponds to the decomposition of the glucose.

\section{Mossbauer analysis}

A typical Mossbauer spectrum of $\mathrm{FM}_{8}$ is shownin(Fig. 6), whereas the computer-fitted parameters for the sample studied are given in Table 3.

Iron is present in 5 forms, $2 \mathrm{Fe}^{2+}$ kinds (15\%) and 3 types of $\mathrm{Fe}^{3+}(85 \%)$

\section{CONCLUSION}

This study describes the preparation of a new material based on clay: montmorillonite $\mathrm{Fe}^{2+}$ shows a high percentages of glucose capture.

- The results showed an important adsorption of glucose (around $40,5 \%$ ) with compensating cation (Fe (II) - KSF) at 8 hours where the exchange of montmorillonite KSF with ferrous ions. ), this sample is identified as $\mathrm{FM}_{8}$.

- The use of infrared spectroscopy allows determining informations about the different absorption bands existing, appearance of new band at $1150 \mathrm{~cm}^{-1}$ correspond to $\vee \mathrm{C}-\mathrm{O}$ and Another band located around $1420 \mathrm{~cm}^{-1}$ is assigned $\delta \mathrm{CH}_{2}+\delta \mathrm{OCH}+\delta \mathrm{CCH}$.

- The $t$ Thermogravimetric analysismakes it possible to follow the loss of mass of the sample as a function of the temperature, In the sample $\mathrm{FM}_{8}-\mathrm{G}$ there is a loss of weight around $350^{\circ} \mathrm{C}, 410^{\circ} \mathrm{C}$ corresponds to the decomposition of the glucose

- Mossbauer spectroscopy were carried out the state of oxidation of ferrous ions in montmorillonite structure.

- This result could confirm that the fixation of glucose was achieved successfully. 


\section{REFERENCES}

1. Crretero,M. I. Clay minerals and Their beneficial upon human health. Appl. Clay Sci. 200,21,155-163.

2. Carrere, A. PhD thesis. University Joseph Fourier of Grenoble (UJF).2002.

3. Morel,R.Cultivatedsoils. Lavoisier, Paris. 1996.

4. Cooper,C.; Jiang,J.Q.;OukiS. Preliminary assessment of polymeric Fe-and Al-modified clays as adsorbents for heavy metal removal in Water Treatment.J ChemTechnolBiotechnol. 2002, 77, 546-551.

5. MalleinRodier, J. R. Handbook of Biochemistry practice.1973, 197.

6. Albert L.Lehninger, Biochemistry "Molecular basis of cell structure functions" end Ed Flammarion Medicine-Sciences. 1977.

7. Trinder, P. Determination of Glucose in Blood using Glucose Oxidase witha alternative oxygen acceptor.Ann.Clin. Biochem.1969,6, 24-27.

8. Stahil, M.; Jorgensen, LGM.;HyltoftPetersen,P. Optimization of preanalytical conditions and analysis of plasma glucose. 1. Impact of the new $\mathrm{WHO}$ and ADA recommendations on diagnosis of diabetes mellitus. Scand. J. Clin. Lab. Invest.2001, 61, 169-180.

9. Boyanton, B.L. Jr.; Blick, K.E. Stability studies of twenty-four analytes in human plasma and serum.Clin.Chem. 2002,48, 2242-2247.

10. Janice,L.; Bishop. Infrared spectroscopic analyses on the nature of water in montmorillonite.Clays and Clay Minerals, 1994, 42,702-716.

11. MurrayH, H. Bentonite, Palygorskite-Sepiolite, and Common Clays», Chapter 6, Elsevier.2 2007.

12. Madejova, J. FTIR Techniques in clay mineral studies. Vibrational Spectroscopy. 2003,31, $1-10$.

13. Alexane,C.; Morel, P.; Bouffant, L. On the infrared adsorption spectra of natural minerals, Bull.Soc. Fr.Ceram, 1966, 71,3-38

14. Tarte P. Study of the silicates by infrared spectrometry.Bull.Soc.Fr.Ceram, D.553 .1962.13-34.

15. Amin,N.C.Merology and physiology of clays treatment of Buruli ulcer in ivory side. J Sci pharm. Biol.2009 , 10, 21-39. 